\title{
Predicting Interest Rates: A Comparison of Professional and Market-Based Forecasts
}

\author{
Michael T. Belongia
}

$\mathbf{I}_{\mathrm{r}}$ Interest rates have varied substantially in recent years. Since 1981, for example, the monthly average three-month Treasury bill rate has ranged between 5.18 percent and 16.30 percent while the Baa corporate bond rate ranged between 9.61 percent and 17.18 percent; the prime rate during this time reached a high of 20.5 percent and fell to a low of 7.5 percent. Interest rate movements are important, of course, because they affect the present value of streams of future payments, that is, wealth. Moreover, the risk of interest rate changes is related directly to the level of interest rates. ${ }^{2}$ During the $1980 \mathrm{~s}$, therefore, firms and individuals have faced substantial exposure to interest rate risk.

There are at least two approaches that can be taken to reduce the magnitude of this problem. The first is to hedge interest rate risk, which has been discussed at length in this Review and elsewhere. ${ }^{2}$ The second is to forecast the likely course of interest rates. This article investigates the reliability of such forecasts in general and assesses the specific usefulness of forecasts by professional economists.

Michael T. Belongla is a senior economist at the Federal Reserve Bank of St. Louis. Paul Crosby provided research assistance.

Interest rate risk, for a firm whose portfolio is composed of streams of future receipts and payments, is measured by the interest elasticity of the portiolio; for a single asset, this can be expressed as $-n(i /$ $1+i)$, where $n$ is the term to maturity. A more general expression for a portfolio of assets and liabilities is derived in Belongia and Santoni (1987). In either case, the level of interest rate risk rises with the interest rate.

2See Belongia and Santoni (1984, 1985).

\section{INTEREST RATE FORECASTS: THEORY AND EVIDENCE}

Given the popular attention that such forecasts command, it is surprising to note what economic theory says about them: they are unlikely to provide accurate insights about the future. This argument is stated clearly by Zarnowitz:

It might be afgued that these are forecasts of people who study the economy (experts), which are quite unlike the expectations of those who act in the economy (agents). On the one hand, the experts are usually credited with more knowledge of the economy at large than the agents have. On the other hand, the experts are often charged with being less strongly motivated to predict optimally than the agents who are seen as having more at stake. "

Economists, at least on one level, lack sufficient incentives to make forecasts that are more accurate than information already available in the marketplace. Moreover, previous studies have shown there is little systematic difference among professional forecasts, at least partly because they "use to a large extent the same data, receive the same news, interact, and draw upon a common pool of knowledge and techniques."4

The key issue, however, really is not whether experts have more (or better) information than the public, but whether individuals who consistently can fore-

3See Zarnowitz (1983), p. 2.

${ }^{4}$ See Zarnowitz (1986), p. 6, and the references cited therein. 
cast interest rates more accurately than the market are likely to make their forecasts public. The reason has to do with individual self-interest. Quite simply, why would anyone reveal valuable insight about the future when he could increase his wealth directly by approw priately trading in financial markets using this information?

If, for example, a person knew that the three-month Treasury bill rate would be 6.50 percent in December, while the futures market currently priced it at 7.00 percent, the forecaster's wealth gain would be limited only by his ability to buy December Treasury bill futures; in this example, he would make a profit of $\$ 1,250$ on every contract he could buy. Certainly, he has no incentive to make the same forecast public without appropriate compensation, at least until he had taken as large a position in the market as he could. Of course, forecasters may have incentives to sell forecasts that are of no value to their wealth; it is not clear, however, why other individuals would pay for such predictions.

As a general rule, the accuracy of economic forecasts varies widely across variables. Previous research has found that predictions of the three-month Treasury bill rate six months into the future by major commercial forecasters are within two percentage points of the actual rate only 67 percent of the time. Thus, if in June, the three-month Treasury bill rate was forecast to be 7 percent in December, there is only a 0.67 probability that the actual December rate would be somewhere between 5 percent and 9 percent. Other studies have shown that error statistics often double in size when the forecast horizon is extended as little as from one to two quarters ahead.?

\section{The Efficient Markets Hypothesis and Interest Rate Forecasts}

A model of interest rate determination demonstrates why individuals are unable (as opposed to unwilling) to forecast interest rates more accurately, on average, than the forecasts already implied by cur-

\footnotetext{
'Treasury bill futures are priced by subtracting the Treasury bill interest rate from 100 . Thus, interest rates of 7.00 and 6.50 percent imply contract prices of 93.00 and 93.50 , respectively. Moreover, each basis-point change in the interest rate is worth $\$ 25$ on the value of a contract. Buying one contract at 93.00 and selling at 93.50 would show a simple profit of 50 basis points $\times \$ 25=\$ 1,250$, abstracting from commission and other costs.

McNees, p. 11.

TTypically, the criterion is root-mean-squared error (RMSE); see McNees (1986). Also, see Zarnowitz (1983).
}

rent spot rates or prices in the interest rate futures markets. This model, known as the efficient markets model, states that the expected interest rate at some specified future point in time, given all information presently avallable, is equal to the current interest rate plus whatever change in the interest rate is suggested by currently available information."

The driving force behind the efficient markets model is the information available to traders in the market and the incentives they have to use this information. Current market rates and expectations of future rates are influenced by changes in information that affect expectations about the future. Because new information is unknown until it actually is released, success in predicting future interest rates depends upon predicting both future changes in the information and the market's reaction to such "news."

\section{An Illustration of the Efficient Markets Model}

One illustration of the efficient markets model applied to actual data is the change in interest rates that follows the weekly Federal Reserve M1 announcement that usually occurs at 4:30 p.m. [EST] each Thursday. The assumption is that the interest rate at 3:30 p.m. just prior to the announcement, fully reflects all currently available information relevant to the Treasury bill rate, including various forecasts of the Fed's yet-tobe-announced change in M1; thus, the available information at 3:30 p.m. includes both actual and predicted data.

When the Fed announces the M1 change at 4:30 p.m., the market's information set is revised with the actual M1 change replacing its predicted value. If no other significant information is released until rates are observed again at 5 p.m., the change in the Treasury bill rate from $3: 30$ to 5 p.m. reflects the market's reac. tion to the news in the M1 announcement. If the actual and predicted M1 values are different, the efficient markets model predicts that interest rates will react to the new information in the Fed's M1 announcement; many studies have found this result empirically. ${ }^{\mathrm{g}}$

\footnotetext{
${ }^{8}$ The efficient markets model applied to interest rate determination can be expressed as:$$
E\left(i_{1+1} \mid \Omega_{1}\right)=i_{1}\left(1+E\left(i_{t+1}-i_{i} l \Omega_{t}\right)\right)_{1}
$$

where $E$ is the expectations operator and $\Omega_{1}$ is the information available to agents at the time forecasts are made. For more detail on this model, see Fama and Miller (1972) or Mishkin (1983).

${ }^{9}$ See Sheehan (1985) and Belongia and Sheehan (1987) for a survey and critique of these studies.
} 
This example demonstrates the major point of the efficient markets model: changes in interest rates depend on changes in information. A forecast that interest rates will be higher six months from now than what already is implied by the underlying term structure really is a forecast that new information will be revealed which will cause market participants to raise the rate of interest. Such forecasts are potentially useful only if the forecasters consistently have better information, on average, than the other market participants generally possess. Or, to state the proposition differently, a useful forecast is not simply an accurate one; it also must tell something about the future that is not already reflected in current market interest rates.

\section{A COMPARISON OF INTEREST RATE FORECASTS}

A comparison of altemative interest rate forecasts is essentially a comparison of information sets that fore casters possess. The futures market, as well as forecasts that simply assume the future will resemble the present, provide useful altermatives to forecasts produced by specialized forecasting services. If all forecasts have similar accuracy, it would suggest that market participants use essentially the same information.

\section{Survey Forecasts}

The information content of economists' forecasts is intriguing for a variety of reasons. Presumably, their specialized training gives them insight to the workings of financial markets. In retum for their services, the economists involved eam relatively large salaries; moreover, some command considerable public attention. The latter group should include those whose forecasts are among the best of competing alternatives.

\section{Market Forecasts}

The futures market offers an interesting perspective on forecasts. At a given point in time, individuals may enter into agreements to buy or sell interest-sensitive assets, such as Treasury bills, at a date as much as two years into the future. The collective actions of investors betting that interest rates will rise from today's level (who will sell Treasury bill futures short) and investors betting that interest rates will fall (who will buy, or go long in, Treasury bill futures) determine, at each moment in time, the "market's" expectation of what interest rates will be at a specified future date. Such forecasts are interesting for two reasons: they reflect all available information held by market partici- pants and these participants have a compelling reason to forecast accurately. If they are wrong, the money lost is their own!

A naive or no-change model is an interesting third alternative because, as previously noted, predicting interest rates really involves predicting changes in information and the market's reaction to this news. If one believes it is impossible to predict actions by OPEC, changes in macroeconomic policy, revisions in economic data and other factors that affect expectations of future interest rates, the best strategy would be to predict no change in information and, hence, no change in interest rates. Certainly, as the length of the forecast horizon grows shorter, the probability of large changes in information (and interest rates) declines as well.

\section{Sources of Forecasts: Professional and Market Data}

The six-month-ahead forecasts of the three-month Treasury bill rate by nine economists surveyed regularly by the Wall Street Joumal were collected over the period December 1981 through June 1986. These forecasts, which are published on or about each January 1 and July 1 , yielded 10 forecast periods and 90 predictions to be evaluated. Each forecast was assumed to be made the day before publication. ${ }^{10}$

Comparable forecasts from the futures market were derived by observing on June 30 the three-month Treasury bill rate implied by the December Treasury bill futures contract and on December 31 the rate implied by the June contract. A larger sample to be used later also employed observations on the March futures contract from the previous September 30 and on the September contract from March 31. These data were compared with actual Treasury bill rates on the day the relevant futures contract ceased trading." The procedure yielded 40 observations, of which 10 coincided with dates of the economists' forecasts. The naive or no-change forecast was obtained by observing the spot Treasury bill rates on the last business days of March, June, September and December and predicting that same rate would exist on the last day of the month six months hence. Again there are 40 observam

\footnotetext{
10The full Wall Street Joumal survey includes many more economists, but only nine individuals have responded consistently since the initial survey in December 1981.

1:Treasury bill futures contracts usually are liquidated in the third week of their terminal months, not the last day of the month as with the economist forecasts.
} 
Chart 1

Treasury Bill Rates: Actual and Predicted

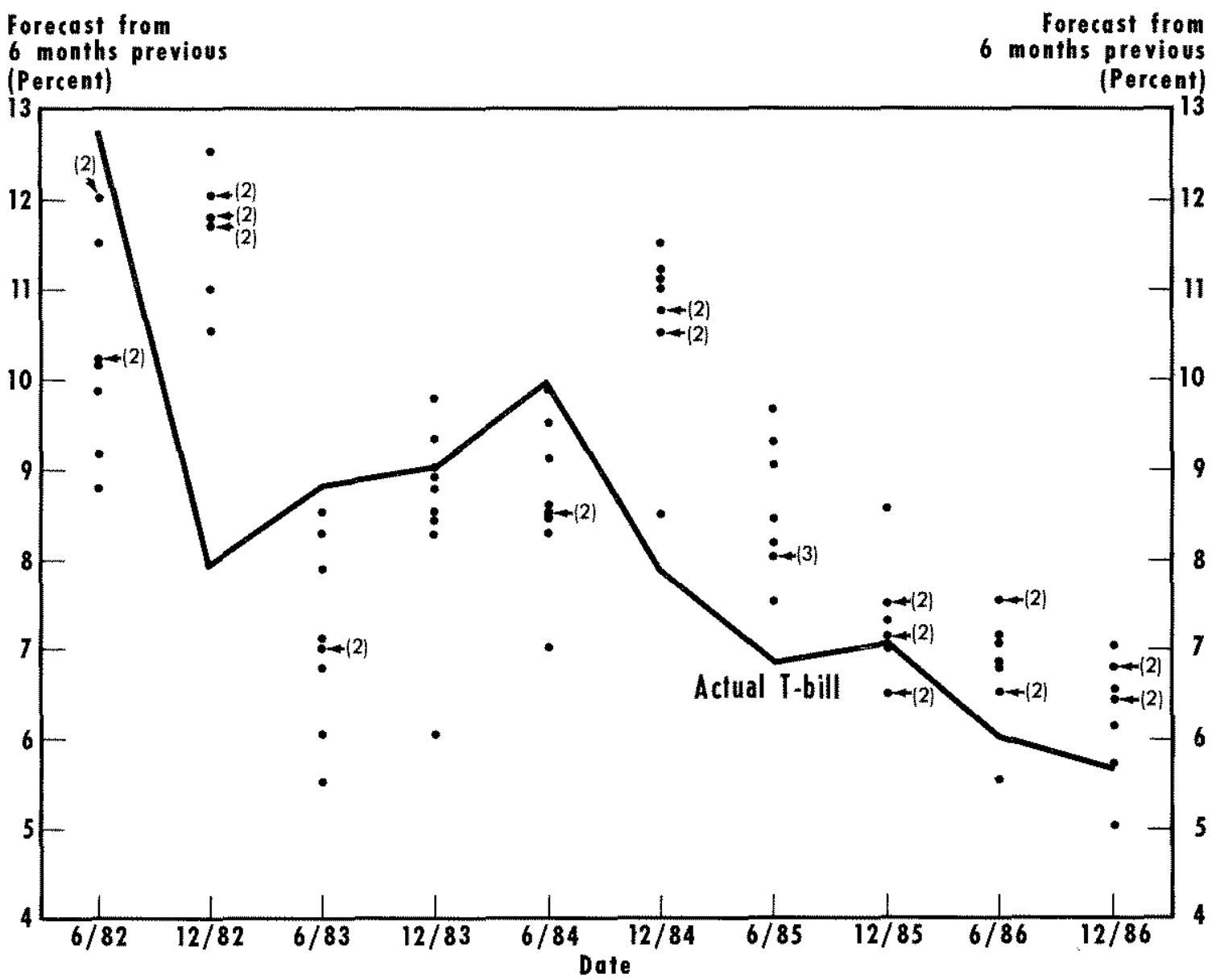

lions over the 1977-86 interval with 10 coinciding with dates of the economist survey. Although this sample of market-based forecasts includes only 10 observations that coincide with the economists' forecasts, it serves as the basis for the first comparison. Subsequent analysis uses the entire sample back to 1977 for a stronger test of forecast accuracy.

\section{Forecasts of Direction of Change}

A first assessment about the accuracy of the profesm sional forecasts was made against a relatively weak criterion, the predicted direction of change. That is, if rates were forecast to increase (or decrease), did they? The individual forecasts relative to subsequent actual values are plotted in chart 1 .
The 90 individual expert predictions correctly forecast the direction of change on 38 occasions, or 42 percent of the time. If interest rate movements are random, a $\mathbf{5 0}$ percent record of accuracy would be expected. ${ }^{12}$ Only one of the nine forecasters guessed

12This type of performance - the strategies of professional investors yielding returns inferior to those of simple rules - is common. For example, the mean equity fund managed by professional institutional money managers rose 16.7 percent in 1986 compared with an 18.7 percent rise in the S\&P 500 index. Moreover, more than 67 percent of the money managers produced returns in 1986 smaller than the general increase in market values, as measured by the S\&P 500; see Wallace (1987). For a more extensive discussion of this result and a similar finding of inferior performance by mutual fund managers over time, see Malkiel (1985), pp. $147-82$, and the references to his chapter 7 . 


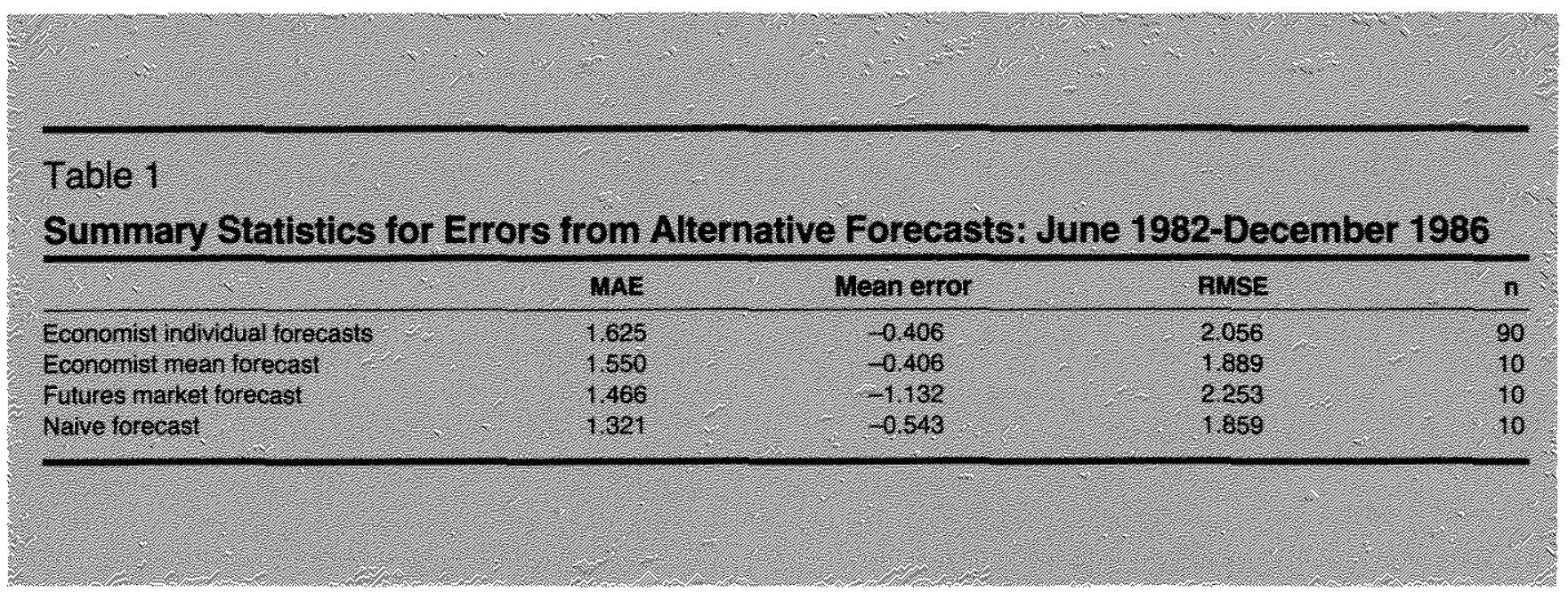

the direction of change correctly more than one-half of the time; he was correct on six of 10 occasions. Three others guessed the correct direction of change on five of 10 occasions. The worst individual performance was two correct predictions.

For the 40 quarterly predictions derived from futures market observations, 22 , or nearly 55 percent, correctly forecast the direction of change. Over the shorter 1982-86 sample, five of 10 directions of change were predicted correctly by the futures market. On the simple criterion of direction of change, the futures market outperforms the economists surveyed ${ }^{13}$

\section{Point Forecasts}

A different criterion by which to evaluate forecasts is a comparison of the point estimates of the predicted changes in interest rates with the actual changes. These comparisons were analyzed several ways. First, forecasts by the nine experts provided 90 individual predictions of the Treasury bill rate. These individual predictions also could be aggregated to form a consensus, or average, prediction for the nine economists at a specific moment in time. The performance of the experts relative to the futures market and naive forecasts first was judged over the short 1982-86 sample that coincided with the economist survey. Differences between actual Treasury bill rates and, respectively, the economist, futures market and naive forecasts were calculated to generate values for forecast errors. All errors were calculated as actual minus predicted values. Table 1 shows the summary statistics for these errors.

\footnotetext{
${ }^{19}$ There is no meaningful way to construct a direction-qf-change criterion for the naive lorecast.
}

The entries in table 1 represent the mean absolute error (MAE), mean error and root-mean-squared error (RMSE) from forecasts for the three-month Treasury bill rate six months into the future. The first two rows are associated with the individual and consensus forecasts from the survey of experts. The third row is based on the differences between the actual Treasury bill rate and the futures market prediction. The fourth row is based on the naive predictions, the differences between current and previous actual rates.

The most interesting aspect of these summary statistics is their remarkable similarity. Of course, this result was predicted by the earlier theoretical discussion, which emphasized that all available information would be reflected in current market rates. The mean errors for all forecasts are negative, indicating that these methods tended to overestimate the interest rate; the futures market, however, tended to be the most bearish forecaster on this account by overpredicting the Treasury bill rate an average of 1.132 percentage points. MAE statistics also are similar, with a range of about 30 basis points between the best (naive) and worst (individual economist). The RMSE statistic, which is a measure of the dispersion of forecast errors, shows the naive and economist consensus to perform

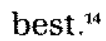

\footnotetext{
${ }^{34}$ The fikely explanation for the futures prediction having the highest RMSE is the method of calculation. The RMSE will tend to be lower for forecasts that made many errors of a similar size relative to forecasts that had smaller errors, on average, but had several very large errors. This result occurs, of course, because calculating the RMSE involves squaring the forecast errors. The effects of random variation in small sampies also is a potential source of distortion. Thus, two very large futures market errors offset a record of generally accurate forecasts as indicated by other statistics.
} 


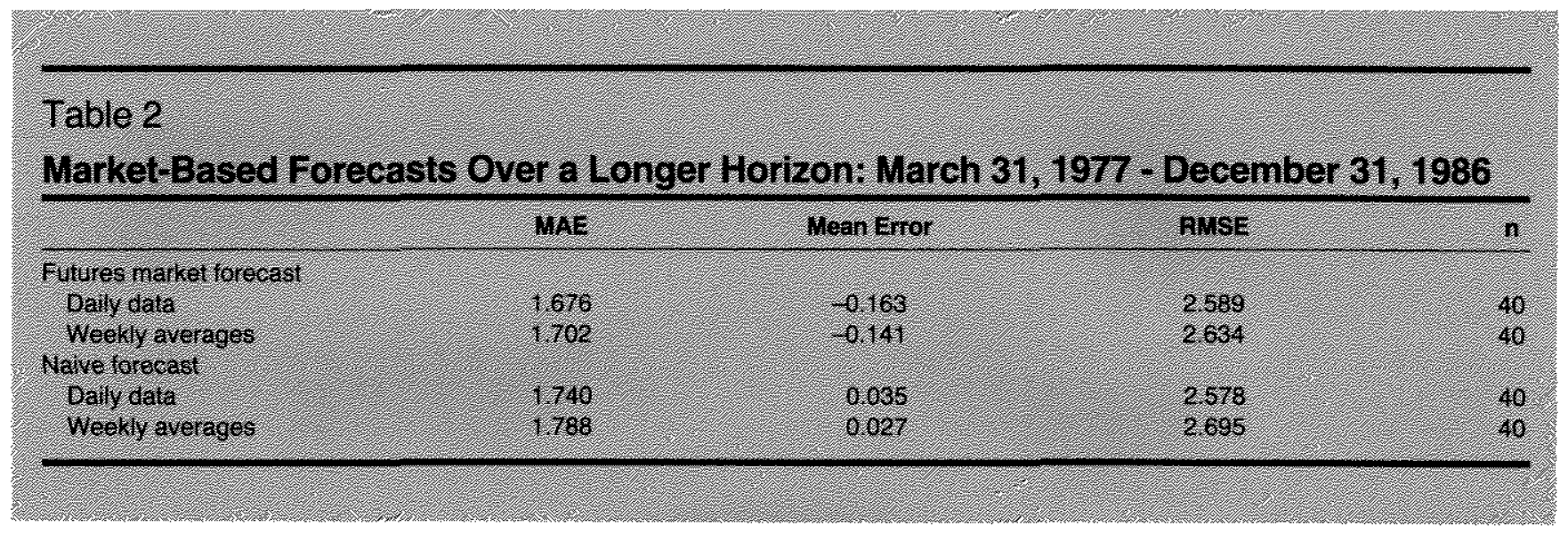

\section{Longer Sample Results for Market-Based Forecasts}

Error statistics from the longer 10-year sample of quarterly observations described earlier are reported in table 2. Because daily interest rate changes are volatile and a large, one-day change could affect the results, forecasts for a specific date also were compared with the average Treasury bill rate for the week in which that date occurred.

Relative to the previous results, the futures market average errors declined substantially to near 15 basis points, compared with the shorter sample mean error of about 113 basis points. MAE and RMSE values increased slightly, however, for the longer sample. The forecast errors do not appear to vary with the use of daily or weekly average values for the terminal period spot rate. The naive forecast also shows slight increases in MAE and RMSE values but its mean error falls about 50 basis points to near zero. Again, while these statistics are not directly comparable with the economist forecasts because of the different sample periods, nothing in them suggests superior performance by the economists.

\section{Market Reaction to Forecasts}

As a final check on the information content of the expert forecasts, daily Treasury bill rates were divided into two groups: those for days when the experts' forecasts were published and those for other trading days. (Recall that the forecasts are useful to the market only if they add to the existing pool of market information, To test whether this is true, equation (1) was estimated:

$$
\begin{aligned}
& \text { (1) } \mathrm{TB}_{1}=0.015+0.998 \mathrm{~TB}_{t-4}+0.049 \text { ANNOUNCEMENT }+\mathrm{e}_{\mathrm{t}} \\
& \text { (1.02) }(657.2) \quad(0.95) \\
& \overline{\mathbf{R}}^{2}=0.99 \quad \text { DW }=1.77
\end{aligned}
$$

where the daily value of the Treasury bill rate $\left(\mathrm{TB}_{\mathrm{t}}\right)$ is regressed on the previous day's value $\left(\mathrm{TB}_{\mathrm{t}-1}\right)$ and a dummy variable (ANNOUNCEMENT) that takes a value of one on the 11 days that the expert forecasts were released ${ }^{15}$ If the expert forecasts add to the market's information, the coefficient for the ANNOUNCEMENT variable should be significantly different from zero; as the t-statistic of 0.95 reveals, however, we cannot reject the hypothesis that the forecast announcements have no effect on Treasury bill rates. Apparently, the Treasury bill market had already incorporated the information underlying these forecasts prior to their public release.

\section{SUMMARY}

Interest rate risk has been substantial in the 1980s, and, by no coincidence, the demand for interest rate forecasts has increased. There are strong theoretical reasons to believe, however, that such forecasts are subject to large errors. Moreover, anyone who could predict interest rates more accurately, on average, than other market participants would have no reason to make his forecasts publicly. Comparisons of interest rate forecast errors support the notion that several market-based forecasts, using information easily accessible to the general public, predict the Treasury bill rate six months into the future as well as a panel of prominent forecasters.

Why, then, do economists make public forecasts of interest rates and seemingly earn large salaries for doing so? Several explanations related to other primary functions of corporate economists seem plausible. First, economists may serve an advertising function for their firms: they are paid, in part, to get the

\footnotetext{
15it is possible to use the January 3,1987 , survey for this estimation.
} 
firm's name mentioned in the press often, and forecasting interest rates is one way to achieve this end. second, economists may provide a managerial insurance function. If a business decision has the potential to cause large losses, managers who have relied on the input of economists cannot be held negligent, in the sense of acting without seeking "the best information available at the time." Finally, forecasting interest rates may be a trivial portion of an economist's overall function; his compensation may be based primarily on analytical performance in other areas. It is unlikely, however, that economists are employed primarily for their ability to predict interest rates more accurately than the market.

\section{REFERENCES}

Belongia, Michael T., and Gary J. Santoni. "Hedging Interest Rate Risk with Financial Futures: Some Basic Principles," this Review (October 1984), pp, 15-25.

"Cash Flow or Present Value: What's Lurking Behind That Hedge?" this Review (January 1985), pp. 5-13.

"Interest Rate Risk, Market Value, and Hedging Financial Portfolios," Joumal of Financial Research (Spring 1987), pp. $47-55$.
Belongia, Michael T, and Richard G. Sheehan. "The Informational Efficiency of Weekly Money Announcements: An Econometric Critique," Joumal of Business and Economic Statistics (forthcoming).

Fama, Eugene F., and Merton $H$. Miller. The Theory of Finance, (Hoit, Rinehart and Winston, tnc., 1972).

Granger, C. W. J. "Comment," Journal of Business \& Economic Statistics (January 1986), pp. 16-17.

Litterman, Robert B. "A Statistical Approach to Economic Forecasting," Journalof Business \& Economic Statistics (January 1986), pp. $1-4$.

Malkiel, Burton G. A Random Walk Down Wall Street, 4th edition, (W. W. Norton and Company, Inc., 1985).

McNees, Stephen K. "Forecasting Accuracy of Alternative Techniques: A Comparison of U.S. Macroeconomic Forecasts," Joumal of Business \& Statistics (January 1986), pp. 5-15.

Mishkin, Frederic S. A Rational Expectations Approach to Macroeconometrics: Testing Policy Ineffectiveness and Efficient-Markets Models (University of Chicago Press, 1983).

Sheehan, Richard G. "Weekly Money Announcements: New Information and its Effects," this Review (August/September 1985), pp. $25-34$.

Wallace, Anise C. "Funds That Put The Pros to Shame," New York Times, February 8, 1987.

Zarnowitz, Victor. "Rational Expectations and Macroeconomic Forecasts," NBER Working Paper No. 1070 (January 1983).

"The Record and Improvability of Economic Forecast. ing," NBER Working Paper No. 2099, Cambridge, MA (December 1986). 